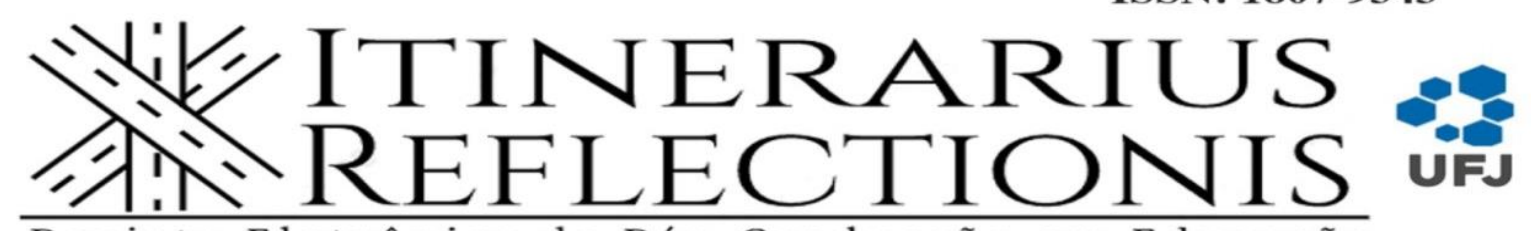

Revista Eletrônica da Pós-Graduação em Educação Universidade Federal de Jataí

Volume, 17, n. 2, ano, 2021

\title{
Livro didático de português: valorização do sujeito negro ou embranquecimento social? ${ }^{1}$
}

Silvio Ribeiro da Silva ${ }^{2}$ Fabiana Lopes Benassi ${ }^{3}$

\begin{abstract}
Resumo: Neste artigo, analisa-se, com base nos procedimentos da pesquisa em Linguística Aplicada, se uma coleção de Livro Didático de Português (LDP) trabalha em prol da valorização do sujeito negro, ou se favorece o embranquecimento social. A análise foi feita na coleção Para Viver Juntos Português, a qual teve um índice de adoção muito alto nas escolas públicas de Jataí-GO. Segundo os Parâmetros Curriculares Nacionais, é parte integrante da História o registro da dificuldade em se tratar da temática do preconceito e da discriminação étnica. O referencial coloca que, na escola, ocorrem manifestações de racismo, discriminação social e étnica por parte de professores, alunos e equipe escolar, por mais que isso ocorra de maneira involuntária ou inconsciente. Sendo o livro didático um importante instrumento pedagógico usado na escola sistematicamente, ele pode criar referências para o aluno. Ele é o material mais usado pelo professor, além de ser, segundo alguns autores, a principal fonte de informação impressa utilizada por grande parte de alunos. Os dados indicaram que a ideologia veiculada pela coleção analisada leva em consideração uma sociedade branca, já que inexistem discussões temáticas que valorizem os aspectos étnicos, sociais e culturais do indivíduo negro, o mesmo ocorrendo em relação a fotografias, imagens e ilustrações, prevalecendo o indivíduo branco na maioria absoluta das vezes.
\end{abstract}

Palavras-chave: Livro didático de Português. Negritude. Embranquecimento social.

\section{Portuguese textbook: black individual's appreciation or the social whitewashing?}

\begin{abstract}
This research analyzed, based on the research procedures in applied Linguistics, if a Portuguese textbook collection works in favor of the black individual's appreciation, or if they benefit the social whitewashing. The analysis was made in the textbook Para Viver Juntos - Português, which had a high incidence rate in the public schools in Jatai-GO. According to the national curricular parameters, it is party of the history the register of the difficulty to treat the prejudice and ethnic discrimination. The benchmark shows that at school occurs racism, social and ethnic discrimination manifestations by part of teachers, student and the school's staff, even thought it happens involuntarily or unconsciously. As the textbook is an important pedagogical tool used inside the school, it can create references to the student. It is the most used tool by the teacher besides being, according to some authors, the main printed information source used majority by part of students. The data indicated that the ideology attach by the collection approaches a white society, since there is no thematic discussions that value the ethnic, social and cultural rights of the black individual, the same happens in the photos, images and illustrations, predominating the white individual most of the times.
\end{abstract}

Key words: Portuguese textbook. Blackness. Social whitewashing.

\footnotetext{
${ }^{1}$ A pesquisa que originou este artigo contou com bolsa de Iniciação Científica (PIBIC/CNPq) e seus resultados contribuem com os estudos realizados dentro do Grupo de Estudos sobre Materiais Didáticos, Ensino e Avaliação - GEMDAV (UFG/CNPq) cuja liderança é ocupada pelo primeiro autor.

${ }^{2}$ Universidade Federal de Jataí. shivonda@gmail.com

${ }^{3}$ Universidade Federal de Jataí. fabianabenassi@ gmail.com
} 


\section{INTRODUÇÃO}

Como sugere o próprio título, este artigo discute se na atualidade o Livro Didático de Português (LDP) trabalha em prol da valorização do sujeito ${ }^{4}$ negro, ou se apela para o embranquecimento social. Parte-se do pressuposto de que a figura social do indivíduo negro não é reconhecida e nem respeitada no LDP, o que acaba por negar o fato de que se trata de um grupo étnico portador de uma cultura e de uma identidade singulares. Negam-se, ainda, os valores representados pela tradição intelectual africana e sua contribuição cultural, como os hábitos, costumes, produção de riquezas, danças e músicas, o candomblé e outras religiões afro-brasileiras, a capoeira, a espiritualidade, a beleza e a inteligência do povo negro. Em geral, o que se nota é uma tentativa de apagamento das culturas consideradas periféricas. As identidades da modernidade atual insistem em que o predomínio cultural seja aquele que se refira às sociedades brancas (HALL, 2014). Nas palavras de Cardoso (2003, p. 15), a humanidade contemporânea tenta se firmar através de um "único paradigma cultural: o do homem (masculino), branco, adulto, culto, racional e materialmente desenvolvido". Posturas como essas são, segundo De Paula (2003, p. 182), "uma das maiores torturas a que os negros são submetidos cotidianamente".

Através da análise de uma coleção de $\operatorname{LDP}^{5}$ dos anos finais do Ensino Fundamental, devidamente avaliada e aprovada pelo Programa Nacional do Livro Didático (PNLD), foi identificado que ideologia é veiculada pelo LDP em relação ao negro e, consequentemente, ao branco, sem vínculo com um discurso de lamentação, mas numa tentativa de dar visibilidade à forma como a negritude é tratada no material didático.

Os objetivos da pesquisa foram: (i) Identificar como se dá a abordagem e a representação do negro em uma coleção de livro didático de Português adotada pela maioria das escolas da rede pública da cidade de Jataí GO; (ii) Discutir como se dá a inclusão da temática étnico-racial no LDP, observando se a representação do negro é feita ou não de maneira estereotipada.

Para o alcance dos objetivos elencados, desenvolveu-se um estudo que se baseia nos procedimentos metodológicos da Linguística Aplicada (LA). Moita Lopes (2005) diz que a pesquisa desenvolvida pela LA é aplicada, ocorre no contexto de aplicação, isto é, no

\footnotetext{
4 O sujeito aqui não é o sujeito passivo, mas o ativo; aquele que, segundo Sobral (2009), possui sua intersubjetividade que, na sua condição de sujeito de sua subjetividade, traz as marcas dos aspectos sociais e históricos da sua relação com a sociedade. Esses aspectos integram gradativamente a sua identidade a partir do reconhecimento do seu ser pelo outro.

${ }^{5}$ A coleção objeto de análise será Para Viver Juntos - Português, de Greta Marchetti, et al. Edições SM.
} 
contexto de ação, e não se faz aplicação em LA, ou seja, a LA não consiste em simplesmente aplicar teorias desenvolvidas pela Linguística.

Além de se enquadrar na perspectiva da LA, esta pesquisa caracterizou-se, ainda, como qualitativo-interpretativista. Nesse tipo de pesquisa, a realidade não pode ser considerada independente do indivíduo por ser ela construída por esse indivíduo. Assim, o pesquisador não tem como se tornar neutro, uma vez que os fatos a serem pesquisados são indissociáveis da sua figura (MOITA LOPES, 2005), sendo ele parte integrante do processo de construção do conhecimento, interpretando os fenômenos e atribuindo-lhes um significado.

A análise visou à identificação de como o LDP constrói a figura hegemônica do branco, levando à sociedade uma ideia de branqueamento social, ou de como ele procura levar até essa sociedade conceitos que contribuem para uma interação étnica, favorecendo o entendimento e respeito a qualquer cultura.

Procurou-se analisar o tratamento dado às ilustrações e imagens que retratam o negro, observando se são utilizadas no sentido de mostrar o sujeito negro como integrante de segmento minoritário da sociedade brasileira, numa situação de invisibilidade, ou se ocorre o contrário.

A coleção em análise, Para Viver Juntos - Português, foi adotada por (65\%) das unidades escolares públicas de Jataí-GO, ao passo que 'Jornadas.Port - Língua Portuguesa', a segunda colocada em índice de adoção, apresentou (35\%) de adoção ${ }^{6}$. Esses valores numéricos justificam a escolha da coleção a ser analisada.

Finalizadas essas considerações iniciais, o artigo segue com a apresentação do problema de pesquisa e dos principais aspectos motivadoras. Aborda-se a importância do livro didático (LD) atualmente, não só por ser o material de acesso a letramentos mais usado pela maioria dos alunos, mas também por vir se tornando um importante objeto de estudos, não só da área da Linguagem, mas também da Educação.

$\mathrm{Na}$ sequência do artigo, aparecem os resultados do estudo, iniciando-se pela apresentação da coleção em análise, mostrando de que partes se constitui, além de considerações sobre a coleção a partir do Manual do Professor, integrante do livro do professor. Essa discussão é composta por dados quantitativos e qualitativos. Em relação aos dados qualitativos, são mostrados alguns exemplos que ilustram as interpretações. Por fim, aparecem as considerações finais, quando os objetivos do estudo são retomados e comentários

\footnotetext{
${ }^{6}$ Fonte: https://www.fnde.gov.br/distribuicaosimadnet/pesquisar. Acesso em 02 de fevereiro de 2021.
} 
em relação ao que os dados e sua análise trouxeram são mostrados, bem como as referências, momento em que se discrimina os autores e as obras serviram para embasamento deste artigo.

\section{APRESENTAÇÃO DO PROBLEMA E PRINCIPAIS QUESTÕES}

Segundo os Parâmetros Curriculares Nacionais (PCN - BRASIL, 1997 - temas transversais), é parte integrante da História do Brasil o registro da dificuldade em se tratar da temática do preconceito e da discriminação étnica ${ }^{7}$. O referencial coloca que, na escola, muitas vezes ocorrem manifestações de racismo, discriminação social e étnica por parte de professores, de alunos, da equipe escolar, por mais que isso ocorra de maneira involuntária ou inconsciente em alguns casos. Atitudes como essas representam uma violação dos direitos dos alunos, professores e servidores discriminados, além de trazer consigo obstáculos que dificultam o livre acesso ao processo educacional pelo sofrimento e constrangimento que causa nessas pessoas.

O documento da Base Nacional Comum Curricular - BNCC - (BRASIL, 2018), dentre as competências gerais, aponta para a necessidade de se exercitar a empatia, o diálogo, a resolução de conflitos e a cooperação, fazendo-se respeitar e promovendo o respeito ao outro e aos direitos humanos, com acolhimento e valorização da diversidade de indivíduos e de grupos sociais, seus saberes, identidades, culturas e potencialidades, sem preconceitos de qualquer natureza.

O surgimento de inúmeros movimentos sociais, vinculados a diferentes comunidades étnicas, foi responsável por um desenvolvimento de resistência a padrões culturais que estabeleciam e sedimentavam injustiças. Aos poucos a sociedade conquistou uma legislação antidiscriminatória. Essa legislação atingiu o ápice quando a Constituição Federal de 1988 passou a tratar a discriminação racial como crime ${ }^{8}$.

Os PCN (BRASIL, 1997) afirmam que ações oficiais equivocadas buscam interpretar o Brasil na perspectiva da homogeneidade cultural e étnica, o que conduz a atitudes de dissimulação do quadro de fato existente. Perdura na sociedade a ideia de um

\footnotetext{
${ }^{7}$ Atualmente, o termo raça não é bem visto, tendo sido substituído por etnia e seus equivalentes, uma vez que o conceito de raça, quando aplicado à humanidade, causa inúmeras polêmicas, porque a área biológica comprovou que as diferenças genéticas entre os seres humanos são mínimas, por isso não se admite mais que a humanidade é constituída por raças.

${ }^{8}$ Segundo o Art. $4^{\circ}$ da Constituição da República Federativa do Brasil, "A República Federativa do Brasil regese nas suas relações internacionais pelos seguintes princípios: [...] VIII - repúdio ao terrorismo e ao racismo; [...]". No Art. $5^{\circ}$, diz-se que "Todos são iguais perante a lei, sem distinção de qualquer natureza, garantindo-se aos brasileiros e aos estrangeiros residentes no País a inviolabilidade do direito à vida, à liberdade, à igualdade, à segurança e à propriedade nos termos seguintes: [...] XLI - a lei punirá qualquer discriminação atentatória dos direitos e liberdades fundamentais; XLII - a prática do racismo constitui crime inafiançável e imprescritível, sujeito à pena de reclusão, nos termos da lei; [...]".
} 
Brasil sem diferenças, formado originalmente pelas três etnias - o índio, o branco e o negro - que se dissolveram, dando origem ao brasileiro. Essa ideia é também difundida na escola e, em geral, nos livros didáticos (LD), o que provoca uma neutralização das diferenças culturais e étnicas e, pior ainda, tende a subordinar uma cultura, ou uma etnia, à outra. Tentando excluir essa questão, divulgou-se uma concepção de cultura e etnia uniformes, desconsiderando as diversas contribuições que compuseram e compõem a identidade nacional.

A BNCC (BRASIL, 2017) discute que a Educação Básica é o momento de abordar a visão plural que forma o Brasil, considerando o aluno como sujeito de aprendizagem. Para isso, deve promover uma Educação que se volte ao acolhimento, reconhecimento e desenvolvimento das singularidades e diversidades que constituem o ser humano.

Ainda nesse alinhamento, o documento diz que a escola deve ser encarada como espaço de aprendizagem, bem como de prática da democracia inclusiva. Assim, deve se fortalecer na prática da não discriminação, não preconceito e respeito à diversidade e à diferença. Essas práticas, se bem desenvolvidas, poderão fazer com que o aluno aprenda a conviver com a diversidade, incluindo, naturalmente, a diversidade étnica, ponto central deste artigo.

Por conta das conquistas obtidas pela comunidade negra no Brasil ao longo do tempo, sua situação social tem melhorado, especialmente após o ano de 1997, a partir da lei 9.459 . Isso favoreceu a ocorrência de uma diminuição de qualquer tipo de tratamento preconceituoso ou discriminatório no LD, não só no de Português. A partir da instauração do Programa de Avaliação do Governo Federal, autores e editores de LD passaram a ter uma preocupação maior com a forma de abordar aspectos relacionados à cultura e à etnia.

De uns tempos para cá, na cultura escolar brasileira, o LD e o material didático ganharam funções que vão desde seu uso como material de apoio ou oficial para o encaminhamento das atividades, como suporte de textos de leitura, até a delimitação da proposta pedagógica (MARCUSCHI e COSTA VAL, 2007). Sendo o LD um importante instrumento pedagógico usado na escola sistematicamente, ele pode criar referências para o aluno. Sendo essa referência positiva, ela é guardada por ele, que tende a incorporá-la às suas práticas sociais cotidianas. Ele é o material mais usado pelo professor, além de ser, também,

\footnotetext{
${ }^{9}$ A Lei 9.459 , de 13 de maio de 1997, corrigiu a Lei 7.716, de 15 de janeiro de 1989 , modificando os artigos $1^{\circ} \mathrm{e}$ $20^{\circ}$, e revogou o artigo $1^{\circ}$ da Lei 8.081 e a Lei 8.882, de 03 de junho de 1994. A lei pune, com penas de até cinco anos de reclusão, além das multas, os crimes resultantes de discriminação ou preconceito de raça, de cor, etnia, religião ou procedência nacional.
} 
segundo Batista (2009), a principal fonte de informação impressa utilizada por parte significativa de alunos e professores.

Segundo Jurado e Rojo (2006), o LD é a principal fonte de leitura de grande parcela do alunado, tendo, assim, papel fundamental na formação de leitores. Por essa razão, segundo as autoras, a análise desse material didático é relevante, uma vez que pode contribuir para que o professor passe a olhá-lo de maneira menos imparcial, interferindo na sua composição de forma a melhorá-lo ou complementá-lo segundo suas necessidades.

Uma justificativa para estudos que se voltam à análise de LDP diz respeito ao fato de ele vir despertando interesse em muitos pesquisadores. Estes tentam entender não só a sua função como instrumento para o ensino, mas também a sua constituição histórica e o impacto causado por ele no ensino/aprendizagem, sua produção, difusão e uso, bem como as relações que produz entre políticas públicas governamentais, elaboração e desenvolvimento de currículos escolares e indústria editorial (ROJO e BATISTA, 2009).

Além disso, carrega, em seu interior, conteúdos que trabalham valores morais, éticos, sociais e patrióticos. Um estudo de um LD permite uma análise das representações e valores que predominam num certo período de tempo, em uma dada sociedade, possibilitando, ainda, a discussão de projetos de construção e de formação social. Para Fonseca (1999, p. 204),

O livro didático e a educação formal não estão deslocados do contexto político e cultural e das relações de dominação, sendo, muitas vezes, instrumentos utilizados na legitimação de sistemas de poder, além de representativos de universos culturais específicos.

Por conta disso, o LD se faz merecedor de análise e de estudo e, nesse sentido, é que se tem buscado garantir, cada vez mais, a qualidade desses materiais, a fim de realmente satisfazer aos anseios didáticos da classe estudantil. Estudos sobre o LD são também uma forma de avaliar se os conhecimentos e conceitos difundidos para a sociedade, repassados por ele, estão de fato apropriados às necessidades dos alunos, levando-se em conta o que preconizam os documentos oficiais.

O impulso dado ao interesse por pesquisas sobre LD pode ser facilmente comprovado pelo notável número de pesquisas sobre LD no Brasil, desde o início da década de 90 (BATISTA e ROJO, 2005). Com a implantação dos sistemas de avaliação do Governo Federal (Programa Nacional do Livro Didático - PNLD ${ }^{10}$ - Ensino Fundamental e Ensino

\footnotetext{
${ }^{10}$ O Programa Nacional do Livro Didático (PNLD) é uma iniciativa do MEC. Seus objetivos básicos são a aquisição e a distribuição, universal e gratuita, de livros didáticos para os alunos das escolas públicas do Ensino
} 
Médio), associada ao surgimento dos Parâmetros Curriculares Nacionais (PCN), em especial, tem sido marcante a crescente preocupação com a configuração/estruturação do LD e com a estruturação de políticas educacionais e propostas curriculares refletidas e implementadas nele.

Identificar a forma como o LDP aborda e representa a imagem do negro é uma forma de verificar se está sendo colocado em prática o que determina a BNCC (BRASIL, 2018) quando afirma que a Educação Básica tem como principal meta a formação de um sujeito global, capaz de compreender a complexidade e a não linearidade das formações sociais. Deve, ainda, derrubar qualquer tentativa reducionista que tende a privilegiar este ou aquele comportamento social, cultural, étnico. Impor uma cultura de branqueamento social é uma forma de discriminação e silenciamento da voz do indivíduo afro descendente.

Convém salientar que o LD usado de forma a estimular o desenvolvimento de atitudes crítico-reflexivas por parte de alunos e professores torna-se um instrumento gerador de consciência crítica, favorecendo o desenvolvimento dos letramentos críticos e protagonistas (MOITA LOPES e ROJO, 2004) ${ }^{11}$. No entanto, o que se observa em relação à diversidade étnica é que o LD é utilizado enquanto veículo das representações hegemônicas que, sendo internalizadas pela classe estudantil, passam a constituir-se no senso comum. Essas representações podem ser prejudiciais à formação da identidade étnico-racial, dificultando a interação grupal dos sujeitos na sociedade da qual são parte integrante, conduzindo as pessoas a acreditarem equivocadamente na existência de identidades homogeneizadas (HALL, 2014).

Um estudo que investigue aspectos relacionados ao LDP usado em escolas públicas se torna pertinente tendo em vista o fato de que a maior parcela da população estudantil se encontra em instituições de ensino dessa natureza. Além disso, tendo em vista as condições dessas instituições, variados problemas podem ser lá detectados, o que, para nós,

Fundamental e Médio brasileiro. Realiza-se por meio do Fundo Nacional de Desenvolvimento da Educação (FNDE). A fim de assegurar a qualidade dos livros que serão adquiridos, o programa desenvolve, a partir de 1996, um processo de avaliação pedagógica das obras neles inscritas, coordenado pela COMDIPE (Coordenação Geral de Avaliação de Materiais Didáticos e Pedagógicos) da Secretaria de Educação Fundamental (SEF) do Ministério da Educação (BATISTA, 2003). O Programa Nacional do Livro do Ensino Médio (PNLEM) teve início em 2004, quando foram avaliados os (LD) de Português e Matemática que seriam distribuídos somente a alunos da rede pública das regiões Norte e Nordeste. A partir de 2006, a distribuição passou a abranger os outros estados e as demais disciplinas já aferidas no Ensino Fundamental. Atualmente, a avaliação dos livros didáticos do ensino médio é também categorizada pela sigla PNLD, da mesma forma que já era em relação à avaliação dos livros didáticos do Ensino Fundamental.

${ }^{11}$ Segundo os autores, é preciso que a escola, a mais importante agência de letramento, trabalhe em sala de aula uma visão que possibilite ao aluno aprender a problematizar o discurso hegemônico (incluindo o 'discurso branco’) da globalização e os significados antiéticos que desrespeitam a diferença (ênfase adicionada). 
motiva uma série de pesquisas que dizem respeito aos conhecimentos por ela propostos, mediante suas práticas pedagógicas, manifestadas, inclusive, pelo material didático. 


\section{RESULTADOS OBTIDOS}

A respeito da coleção que foi objeto de análise, o Guia do PNLD (BRASIL, 2016) diz que cada volume apresenta nove capítulos, os quais recebem o nome do gênero que será estudado e se organizam em torno de dois textos: Leitura 1 e Leitura 2. Esses textos são seguidos de seções e subseções relativas aos quatro eixos de ensino: leitura, produção de texto oral, produção de texto escrito e análise linguística.

Os gêneros organizadores dos volumes são: Volume 6, "Narrativa de aventura", "Conto popular", "História em quadrinhos", "Notícia", "Relato de viagem e diário de viagem", "Poema", "Biografia e autobiografia", "Entrevista" e "Revisão"; Volume 7, "Conto", "Mito e lenda", "Crônica", "Reportagem", “Artigo expositivo de livro paradidático e de livro didático", "Poema e cordel", "Carta do leitor e carta de reclamação", "Artigo de opinião" e "Revisão"; Volume 8, "Conto de enigma e conto de terror", "Romance de ficção científica e conto fantástico", "Diário íntimo e diário virtual", "Verbete de enciclopédia", "Texto dramático", "Poema", "Artigo de opinião", "Carta do leitor e debate" e "Revisão"; Volume 9, "Conto psicológico", "Conto social e conto de amor", "Crônica esportiva e reportagem", “Artigo de divulgação científica", "Texto dramático e roteiro", "Artigo de opinião", "Resenha crítica", “Anúncio publicitário e anúncio de propaganda" e "Revisão".

O Manual do Professor aponta a importância de um trabalho voltado para o desenvolvimento de competências e habilidades, apresentando os princípios privilegiados pela coleção: a competência leitora, a resolução de problemas e a discussão de valores. Também expõe as concepções que fundamentam a proposta quanto à linguagem, leitura, produção de texto, reflexão linguística, linguagem oral, avaliação e ao papel dos jogos na aprendizagem; descreve a metodologia adotada, oferece textos teóricos de apoio e sugestões de livros e sites para o professor.

Em relação ao encaminhamento do Manual do Professor de que a coleção deve discutir valores, o que os dados mostraram é diferente disso, pelo menos em relação ao tema central discutido neste artigo. Como poderá ser visto na sequência, ocorrem pouquíssimos apontamentos sobre a questão da negritude, o que mostra um possível desalinhamento entre o que o Manual do Professor apresenta e o que o livro do aluno de fato traz.

$\mathrm{Na}$ coleção inexistem considerações sobre aspectos voltados às questões sociais, como a negritude. Além disso, textos que contemplem a heterogeneidade sociocultural brasileira ou que manifestem a variação linguística do Português nos âmbitos social e regional são inexpressivos em termos quantitativos. Essa inexpressividade fere o que determina o 
documento da BNCC (BRASIL, 2018), já que ele enfatiza a relevância de se discutir o fenômeno da variação linguística e das variedades, abordando tanto as que são prestigiadas quanto as estigmatizadas, não deixando de lado a problematização a respeito do preconceito linguístico, questionando as bases desse preconceito de maneira crítica.

No Guia do PNLD (BRASIL, 2016) aparece a orientação para que seja recomendado aos alunos as leituras dos livros de literatura infanto-juvenil sugeridos na seção "Para Saber Mais", integrante da coleção. Segundo o guia, essa ampliação da oferta de leitura deve incluir textos que contemplem a heterogeneidade étnica, social e regional do Brasil, bem como a diversidade da produção cultural do país. A avaliação do PNLD indica que as questões da etnia são desconsideradas pela coleção, o que pode ser comprovado de maneira mais detida na análise que será apresentada na sequência.

No Volume do $6^{\circ}$ ano, por exemplo, aparece uma atividade de leitura com um texto intitulado 'Capoeira sobre duas Rodas'. O texto traz a notícia de um mestre de capoeira que fez uma viagem dos Estados Unidos até a Bahia de bicicleta. Poderia ser um bom momento para discutir os aspectos culturais e sociais da capoeira, especialmente para ressaltar o valor que ela tem para a comunidade negra, porém inexistem considerações a esse respeito no texto e nas questões sobre ele. Nas atividades, as questões são de mera decodificação de dados apresentados no texto, ou para que o aluno interiorize informações sobre o gênero em destaque (notícia).

Ainda sobre o texto mencionado, seu personagem principal é o Mestre Acordeon. Seu nome original é Ubirajara Almeida. Ele é um mestre da capoeira, mas não é um homem negro, como pode ser visto na reprodução da fotografia na sequência.

Figura 1: Exemplo ilustrativo 1

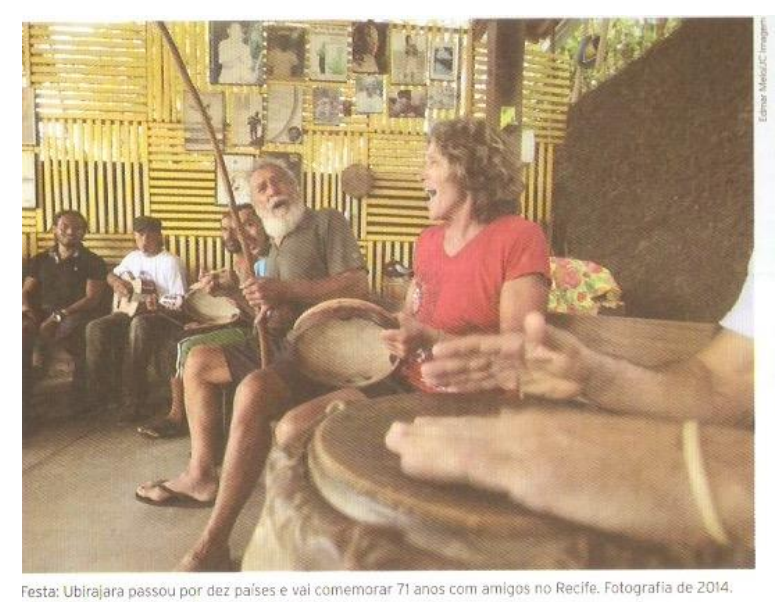

Fonte: LD 'Para Viver Juntos' (Vol. 6, p. 136) 
Associar à capoeira uma pessoa que está distante das raízes étnicas dessa manifestação cultural tende a descaracterizar a verdadeira raiz da capoeira, uma expressão cultural brasileira, originalmente criada pelos negros escravos no Brasil. A atitude do LD parece estar associada à ótica do embranquecimento ao vincular à capoeira um homem branco, ao invés de associar à expressão cultural seus verdadeiros idealizadores e praticantes em sua maioria. Segundo Silva (2004, p. 52), “omitindo e minimizando a história, os valores culturais, o cotidiano e as experiências do negro, o livro concorre significativamente para o recalque da sua identidade étnica e seu branqueamento mental e físico", não contribuindo em nada para sua valorização.

Sabe-se que a escola desempenha um importante papel na construção das identidades sociais (MOITA LOPES, 2010, p. 38). Por se tratar de um ambiente diversificado, é essencial que todos os gêneros, etnias e classes sejam representados de maneira que os alunos possam reconhecer o seu espaço na sociedade, bem como o espaço de demais pessoas. A análise dos quatro volumes apresentou números discrepantes no que se refere à abordagem e/ou representação do sujeito negro, seja ela através da ilustração, fotografia, imagem ou texto para leitura/atividades. A desigualdade de retratação do negro, se comparada a do branco, dispensa levantamentos específicos, visto que é nitidamente visível simplesmente ao folhear algumas páginas de qualquer capítulo ao longo dos volumes.

O Volume do $6^{\circ}$ ano, em relação aos textos não verbais (imagem, fotografia e ilustrações), apresenta o maior índice e ocorrência da coleção: (12\%), equivalente a 49 (quarenta e nove) representações do total de 401 (quatrocentos e um) textos não verbais. Indo na contramão disso, é o volume que mais retrata os estereótipos impostos pelo preconceito racial - 44 (quarenta e quatro) figuras neutras ${ }^{12}, 4$ (quatro) estereotipadas e 1 (uma) valorizada.

Um exemplo da apresentação de texto não verbal que reforça o estereótipo é a fotografia de uma garota, reproduzida na sequência.

\footnotetext{
${ }^{12}$ Estamos categorizando como neutras as imagens, fotografias e/ou ilustrações que simplesmente apresentam pessoas negras, mas sem fazer menção a elas.
} 
Figura 2: Exemplo ilustrativo 2

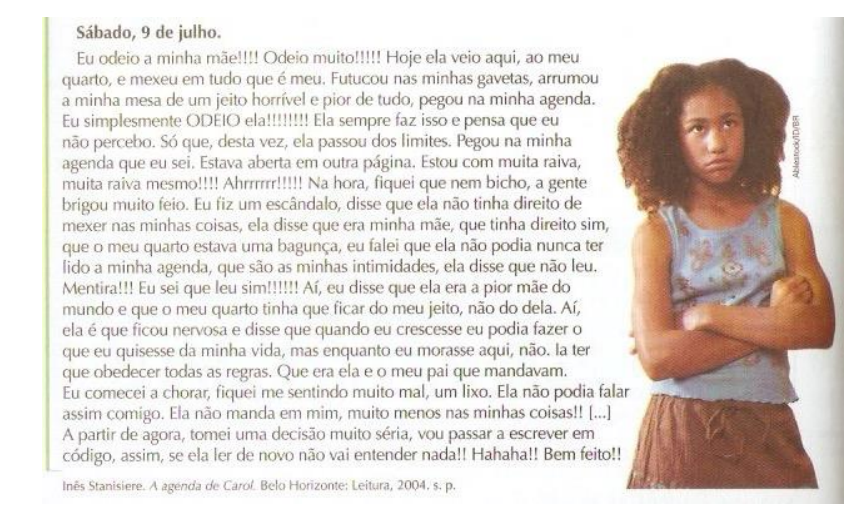

Fonte: LD 'Para Viver Juntos’ (p. 40, Capítulo 1, Volume 6)

A fotografia é bastante relevante por ser um símbolo importante, dado que esse tipo de exibição é completamente ligado ao registro do real, ou seja, um ser humano de fato, e não ilustrações ou imagens dele. Essa fotografia acompanha o trecho de um livro cujo título é "A agenda de Carol". O trecho narra o episódio em que a personagem descobre que sua mãe mexeu em suas coisas e fica muito irritada, sendo possível identificar tal irritação na utilização da pontuação e uso de letras maiúsculas - "Eu odeio a minha mãe!!!! Odeio muito!!!! [...]Eu simplesmente ODEIO ela!!!!!!!!” (p. 40, linhas 1 e 4). Em análise da conversação, segundo Marcuschi (2003), indica-se, na escrita com letras maiúsculas, uma intenção de ênfase vocal ao que foi dito, aproximando-se do grito. E a repetição de um sinal de pontuação indica ênfase naquilo que se pretende dizer, seja uma pergunta, seja uma exclamação, como no caso do exemplo apresentado.

A fotografia é de uma garota negra com a fisionomia contrariada, os braços cruzados com um dos punhos fechado e a aparência vingativa. Santos (2001, p. 99) acena a posição do ser negro atrelada a um lugar previamente imposto, "o lugar de inferior, de menos inteligente, de menos capaz, de violento, de tribal" (ênfase adicionada). No exemplo em específico, há pouco apresentado, é possível perceber associação do sujeito negro a sentimentos de ódio, atitude que não colabora de forma alguma com a desvinculação da cultura de violência. Embora haja a possibilidade da fotografia que acompanha o trecho ter sido utilizada para simbolizar a 'Carol original', outras imagens poderiam acompanhar o episódio, como um diário, a própria capa do livro ou um objeto que remetesse ao ambiente onde a personagem poderia estar. Neste momento, por se tratar de uma associação negativa, a criança negra poderia, preferivelmente, não ser evidenciada. 
Os dados referentes ao Volume 7 não apresentam grandes variações, exceto pela ausência de abordagens negativas (nenhum estereótipo). Ocorrem (9\%) de abordagens em textos não verbais, de um total de 348 (trezentos e quarenta e oito) textos dessa natureza. A respeito dos textos verbais, ocorrem (3\%) de abordagens de um total de 160 (cento e sessenta) textos. Para as atividades sobre os textos verbais, ocorre 1 (uma) abordagem, de um total de 517 (quinhentos e dezessete) questões, equivalendo a menos de (1\%) do total.

No Volume 8, a representação cai para (6\%), de um total de 360 (trezentos e sessenta), em relação aos textos não verbais. Já nos textos verbais, isso ocorre em $(2 \%)$ de um total de 178 (cento e setenta e oito) textos. Nas atividades sobre os textos verbais, a abordagem ocorre em apenas 3 (três) questões, equivalendo a menos de (1\%) do total.

Como exemplo, tem-se uma atividade relacionada ao tema "racismo" em que aparecem duas questões sobre a temática, conforme pode ser visto na sequência. Frente à relevância da discussão, se houvesse um quantitativo de questões próximas a esta, o LDP estaria mais próximo daquilo que prescrevem os referenciais, como mostrado na seção 2 deste artigo.

Figura 2: Exemplo ilustrativo 2

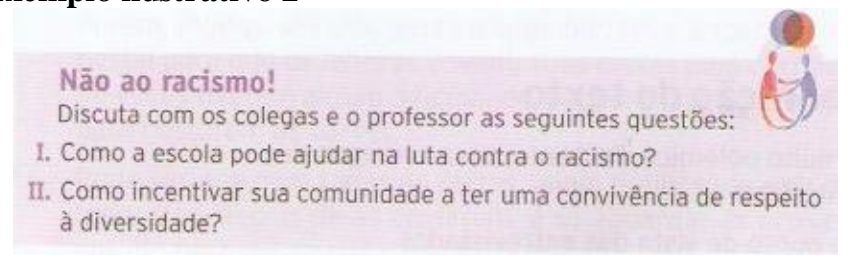

Fonte: LD ‘Para Viver Juntos’ (p. 243, Capítulo 8, Volume 8)

As ocorrências de representação por imagem, fotografia ou ilustração no Volume 9 são (11\%), de um total de 315 (trezentos e quinze) textos não verbais. Para os textos verbais no volume, aparece apenas 1 (uma) atividade, de um total de 150 (cento e cinquenta), equivalendo a menos de $(1 \%)$. Menos de $(1 \%)$ também ocorre no volume a respeito das questões sobre os textos verbais, as quais totalizam 522 (quinhentos e vinte e dois).

A análise dos 4 (quatro) volumes da coleção mostra nitidamente a presença predominante do padrão branco europeu nas ilustrações, imagens e fotografias. Os textos e reflexões a seu respeito tampouco valorizam a cultura negra. Silva (2004, p. 39) explica que essa "ausência gritante pode se traduzir na tentativa de negar a sua [do sujeito negro] existência".

A presença do sujeito negro, mas sem indicações que valorizem sua figura, é uma espécie de estratégia da editora, tendo em vista as exigências da avaliação oficial do Governo 
Federal (Programa Nacional do Livro Didático), bem como as indicações da BNCC nos vários momentos em que reforça a necessidade de uma abordagem que não só valorize a diversidade, mas que também combata todo tipo de preconceito.

A coleção que se eximir de apresentar os grupos sociais minoritários pode ser penalizada na avaliação, correndo o risco de ser, inclusive, excluída do processo avaliativo, o que implicaria num prejuízo muito grande para os autores e, especialmente, para a editora. Ressalta-se que apenas ter a figura do negro presente nas páginas da coleção não significa que haverá valorização de sua imagem social.

Em se tratando da valorização do sujeito negro, os dados apresentam aspectos positivos em 3 (três) volumes, equivalendo a (2\%) do total de imagens. Rosemberg (2003, p. 136) nos diz que ocorrem com grande frequência ilustrações que apresentam “[...] o negro escravo, vinculando-o à passagem daquela condição à de marginal contemporâneo, pouco trabalhando a diversidade de sua condição". Mesmo havendo valorização, os dados quantitativos demonstram que ela é ínfima, comprovando a desigualdade, em geral associada à inferioridade do sujeito negro. Tudo isso indica a tese tão recorrente de uma ideologia do embranquecimento e uma desvalorização da imagem do negro, apontando para uma tentativa de anulação da possibilidade de sucesso que o negro pode obter, reforçando os ideais de estereótipo negativo, ressaltando que apenas pessoas brancas obtêm sucesso na vida.

Um exemplo positivo ocorre com a ilustração de um garoto negro pensando no futuro. No seu pensamento, ele aparece adulto, de terno, com uma pasta maleta executiva em uma mão e com o diploma na outra. A ilustração, acompanhada da oração 'o que você vai ser daqui dez anos?', diz respeito a uma atividade da seção de gramática denominada 'Questões da escrita', em que os alunos estão estudando a diferença de uso de 'a' e 'há', conforme exemplo na sequência.

Figura 3: Exemplo ilustrativo 3

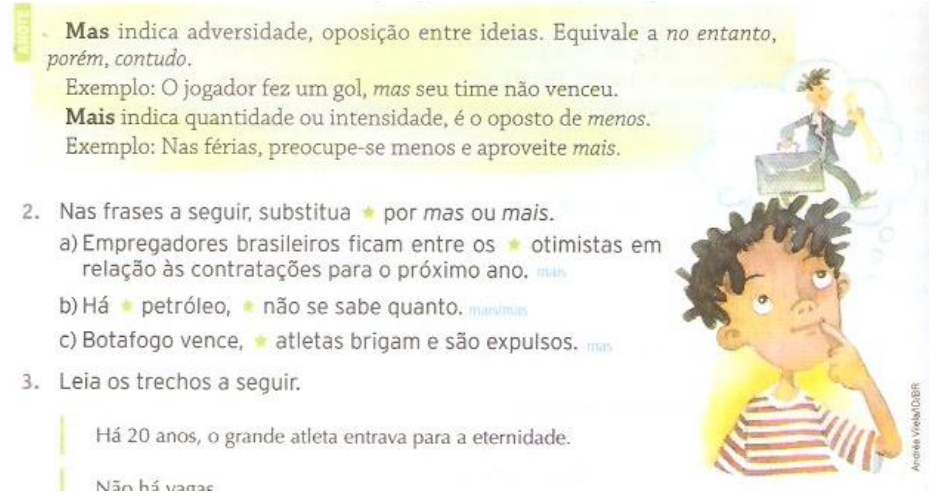


Fonte: LD 'Para Viver Juntos’ (p. 236, Capítulo 7, Volume 7)

A ilustração favorece o sujeito negro pelo fato de que ela pode colaborar com a internalização, por parte da sociedade, de uma imagem positiva desse sujeito, por considerar que ele pode exercer profissões valorizadas socialmente.

\section{CONSIDERAÇÕES FINAIS}

Os objetivos levantados para a pesquisa que originou este artigo consistiram em identificar como se dá a abordagem e a representação do negro em uma coleção de LD de Português adotada pela maioria das escolas da rede pública da cidade de Jataí GO, bem como discutir a forma trabalhada e a inclusão da temática étnico-racial no LDP, observando se a representação do negro foi feita ou não de maneira estereotipada.

Após análise dos 4 (quatro) volumes da coleção, é nitidamente perceptível a presença predominante do padrão branco europeu nas ilustrações, imagens e fotografias. Os textos e reflexões a respeito desses textos tampouco valorizam a cultura negra.

É inquestionável que os LDP melhoraram (bastante) após a implantação do PNLD. Infelizmente é também inegável que ainda continuam (re)produzindo e veiculando um discurso que trata o branco como representante da espécie humana, situando o negro à margem da sociedade, mantendo-o circunscrito a determinadas temáticas (geralmente associadas à escravidão) e espaços sociais (em geral como subordinado ou subalterno).

A postura do LD perante o silenciamento da questão da diversidade cultural associada aos grupos étnicos na coleção parece pretender disseminar a ideia de que no Brasil não existem diferentes e variados grupos sociais e étnicos. Isso reforça a perspectiva da existência de uma nação branca, que pela miscigenação acabará por erradicar o negro da população brasileira. Essa ideia se desenvolve a partir do modo como se caracteriza o negro ao longo da História mundial, de forma estereotipada e/ou inferior, criado com a única finalidade de servir, e servir o branco, considerado superior. Omitindo e minimizando a história, os valores culturais, o cotidiano e as experiências do indivíduo negro, o LDP concorre significativamente para o recalque da sua identidade étnica e seu branqueamento mental e físico (SILVA, 2004).

O papel da escola vai além de ensinar conteúdos, já que ela é fundamental para a formação social e cultural do sujeito. Os alunos acreditam em seus professores, que creem no material didático utilizado. Como os dados mostraram, pelo menos em relação à coleção analisada, não ocorre contribuição para que o aluno negro se identifique como tendo prestígio 
social. O LD possui grande importância no sistema educacional do Brasil, seu papel contribui para a construção do aluno e deve ser livre de qualquer estereótipo, caso contrário o conhecimento da realidade de determinados grupos pode não ser devidamente contemplado.

Segundo Cavalleiro (2001), a sala de aula é a reprodução do padrão tradicional da sociedade, sendo os alunos parte da representação dela e cujo comportamento, geralmente, está relacionado à maneira como lhes foi repassado, seja de forma direta, através dos ensinamentos da família ou responsáveis, seja de forma indireta, momento em que o LD pode exercer alta influência. Cavalleiro (2001, p. 153) complementa que "a utilização de materiais pedagógicos ou de apoio que não contemple a diversidade dos alunos e alunas presentes na escola também colabora para reforçar a percepção de que em nossa sociedade determinado grupo é mais valorizado".

O professor, no momento em que reflete sobre a ausência de abordagem diversificada, deve notar claramente a necessidade de utilizar o material de forma crítica e debater o tema em aula, para que, nessa oportunidade, possa munir os cidadãos ali presentes de informações, conhecimentos e compreensões (SANTOS, 2001). No caso da coleção em análise, a avaliação do PNLD, como dito, indica a necessidade de abordar a questão da heterogeneidade étnica, social e cultural do Brasil. O aluno está em um ambiente ideal para aquisição de múltiplos saberes e, no caso do negro, enquanto enfrentar ausência de frequência na retratação ou sua presença ser limitada a determinadas temáticas, a identificação será mais difícil. Calado (2014) diz que esse processo de identificação é importante uma vez que permite ao sujeito estabelecer laços afetivos com um grupo ou reconhecer traços que percebe no outro, ou reconhecer nos outros traços que deseja para si. A autora diz isso citando Costa (2012), quem diz, também, que a presença do negro de modo positivo no ambiente escolar (incluindo no material didático) pode favorecer a identificação dos alunos negros com um modelo positivo, afastando estereótipos.

Considerando a lei 9.459 e as práticas sugeridas pela BNCC, a expectativa era identificar que a temática étnico-racial fosse abordada, representada e discutida de forma a valorizar esses sujeitos, proporcionando ao aluno um reflexo positivo desde infância à vida adulta. Em um país onde 56,2\% da população se autodeclara preta ou parda (segundo dados da Pesquisa Nacional por Amostra de Domicílios (PNAD) 2019) ${ }^{13}$, esperávamos que o LDP traduzisse de forma conveniente esse padrão.

\footnotetext{
${ }^{13}$ Fonte: https://educa.ibge.gov.br/jovens/conheca-o-brasil/populacao/18319-cor-ou-raca.html. Acesso em 19 de junho de 2020.
} 
Em pesquisa realizada no ano de 2004, Silva (2004, p. 67) analisou a discriminação do negro no LD e concluiu que "em todos os livros analisados o branco foi o personagem predominante, quer nas ilustrações, quer nos textos, enquanto o negro apareceu como minoria [...] de forma estereotipada”. Após esse período, o PNLD passou por diversas transformações avaliativas em busca de aprimoramento. Hoje, 16 (dezesseis) anos após a pesquisa da autora, identifica-se de forma desoladora como a realidade daquele momento ainda se faz muito atual.

Um ponto positivo para a coleção em observação diz respeito à ausência de vocabulário de cunho racista, o que pode "construir a igualdade entre os alunos a partir de um ideal de democracia racial" (GONÇALVES, 1987, p. 28), anulando processos discriminatórios.

Deve ser extinguido o silenciamento em relação ao apagamento do sujeito negro. $\mathrm{O}$ assunto deve ser debatido e abordado dentro e fora da sala de aula, contemplando a diversidade. Uma Educação mais inclusiva poderá desempenhar relação fundamental para construção de uma sociedade evoluída, principalmente em questões de respeito.

\section{Referências}

BATISTA, A. A. G. A avaliação dos livros didáticos: para entender o programa nacional do livro didático (PNLD). In: BATISTA, A. A. G. e ROJO, R. (Org.). Livro didático de língua portuguesa, letramento e cultura da Escrita. São Paulo: Mercado de Letras, 2003. p. 25-67.

. Um objeto variável e instável: textos, impressos e livros didáticos. In: ABREU, M. (org.)

Leitura, história e história da leitura. Campinas: Mercado de Letras, 2009.

BATISTA, A. A. G. e ROJO. R. H. R. Livros escolares no Brasil: elementos para um estado do conhecimento. In: COSTA VAL, M. da G. \& MARCUSCHI, B (Org.) O livro didático de Língua Portuguesa - Letramento, inclusão e cidadania. BH: Autêntica/CEALE, 2005.

BRASIL (SEF/MEC). Parâmetros curriculares nacionais: pluralidade cultural e orientação sexual, temas transversais, Volume 10. Brasília, 1997.

BRASIL. Constituição da República Federativa do Brasil. Brasília/DF: Senado, 1988.

BRASIL. Lei n 9.459, de 13 de maio de 1997. Diário Oficial da União. Brasília/DF, 1997.

BRASIL. Lei $n^{0}$ 10.639, de 9 de janeiro de 2003. Diário Oficial da União. Brasília/ DF, 2003.

BRASIL. Ministério da Educação. PNLD 2017: língua portuguesa - Ensino fundamental anos finais / Ministério da Educação - Secretaria de Educação Básica SEB - Fundo Nacional de Desenvolvimento da Educação. Brasília, DF: Ministério da Educação, Secretária de Educação Básica, 2016. 
BRASIL. Base Nacional Comum Curricular: Educação Infantil e Ensino Fundamental. Brasília: MEC/Secretaria de Educação Básica, 2018.

CALADO, M. da G. Escola e enfrentamento do racismo: as experiências das professoras ganhadoras do Prêmio Educar para a Igualdade Racial. 2014. 217 f. Tese. (Doutorado em Educação). Faculdade de Educação, Universidade de São Paulo, São Paulo, 2014.

CARDOSO, C. M. Tolerância e seus limites: um olhar latino-americano sobre a diversidade e a desigualdade. São Paulo: Editora UNESP, 2003.

CAVALLEIRO, E. Educação anti-racista: compromisso indispensável para um mundo melhor. In: Racismo e anti-racismo - repensando nossa escola. São Paulo: Summus, 2001.

DE PAULA, R. C. de. Construindo consciência das masculinidades negras em contexto de letramento escolar: uma pesquisa-ação. In: MOITA LOPES, L. P. da (org.). Discursos de identidades: discurso como espaço de construção de gênero, sexualidade, raça, idade e profissão na escola e na família. Campinas SP: Mercado de Letras, 2003. p. 181-208.

FONSECA, M. da C. F. Os limites do sentido no ensino da matemática. Educação e pesquisa - revista da faculdade de educação da USP, p. 147-162, Jan/jun1999.

GONÇALVES, L. A. O. Reflexão sobre a particularidade cultural na educação das crianças negras. Cadernos de Pesquisa, São Paulo, n. 63, p. 27-29, nov. 1987.

HALL, S. A identidade cultural na pós-modernidade. Rio de Janeiro: DP e A, 2014.

JURADO, S. e ROJO, R. H. R. A leitura no ensino médio: o que dizem os documentos oficiais e o que se faz? In: BUNZEN, C. \& MENDONÇA, M. (Org.). Português no ensino médio e formação do professor. São Paulo: Parábola Editorial, 2006. p. 37-55.

MARCHETI, G. et al. Para viver juntos - Português. São Paulo: Edições SM, 2015.

MARCUSCHI, L. A. Análise da conversação. São Paulo: Ática, 2003.

MARCUSCHI, B. e COSTA VAL, M. G. (Org.) O livro didático de Língua Portuguesa Letramento, inclusão e cidadania. BH: Autêntica/CEALE, 2007.

MOITA LOPES, L.P. e ROJO, R.H.R. Linguagens, códigos e suas tecnologias. In: SEB/MEC (org.). Orientações Curriculares do Ensino Médio. $1^{\text {a }}$ ed., Brasília, MEC/SEB, 2004. p. 1459.

MOITA LOPES, L. P. Afinal, o que é linguística aplicada? In: MOITA LOPES, L. P. Oficina de linguística aplicada. Campinas: Mercado de Letras, 2005. p. 17-26.

Identidades fragmentadas: a construção discursiva de raça, gênero e sexualidade em sala de aula. Campinas SP: Mercado de Letras, 2010.

ROJO, R. e BATISTA, A. Apresentação - cultura da escrita e livro escolar: propostas para o letramento das camadas populares no Brasil. In: ROJO, R. H. R. \& BATISTA, A. A. G. 
(Org.). Livro didático de língua portuguesa, letramento e cultura da escrita. Campinas: Mercado de Letras, 2009. p. 7-24.

ROSEMBERG, F.; BAZILL, C. e SILVA, V. B. da. Racismo nos livros didáticos brasileiros e seu combate: uma revisão da literatura. Educação e Pesquisa, 2003, v. 29, n. 1, p. 125-146.

SANTOS, H. Discriminação racial no Brasil. In: SABÓIA, G. V.; GUIMARÃES, S. P. (Org.). Anais de Seminários Regionais Preparatórios para a Conferência Mundial contra o Racismo, Discriminação Racial, Xenofobia e Intolerância Correlata. Brasília: Ministério da Justiça, 2001.

SILVA, A. C. A discriminação do negro no livro didático. Salvador: EDUFBA, 2004.

SOBRAL, A. Do dialogismo ao gênero: as bases do pensamento do Círculo de Bakhtin. Campinas, São Paulo: Mercado de Letras, 2009. 